SJFA

$$
\text { الدورية العمية لكلية الفنون الجميلة - جامعة الإسكندرية }
$$

Scientific Journal of the Faculty of Fine Arts Alexandria University

Print ISSN: $2356-8038 \quad$ Online ISSN: $2535-227 x$

World Health Organization.

تصميم أغلفة طعام الأطفال في الفئة العمرية بــ سنوات في المملكة العربية السعودية

$$
\text { ربا حسن أبو حسنة2 - 2 - 2 }
$$

الملخص

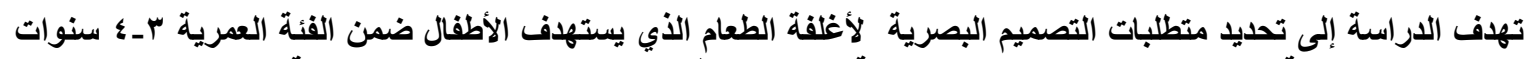

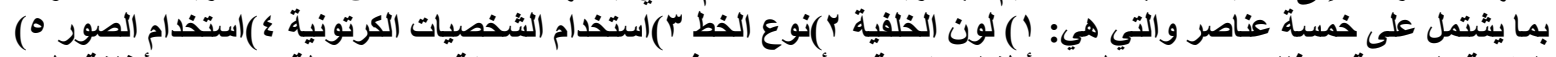

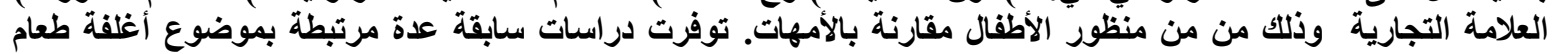

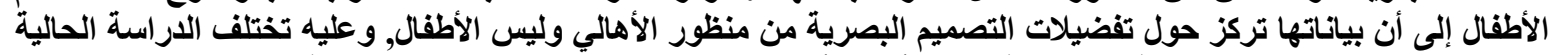

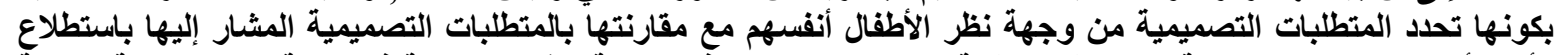

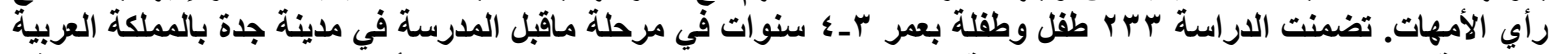

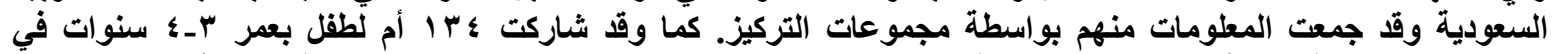

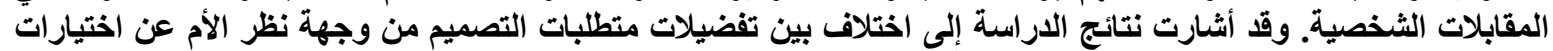

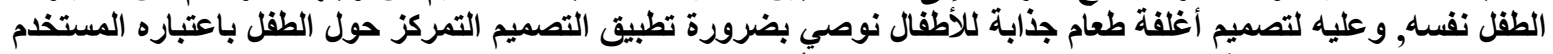

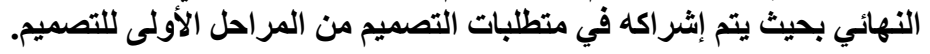

الكلمات الدالة: التصميم الدتمركز حول الطفل ، تصميم الأغلفة ،تغليف الأطعدة، طعام الأطفال، السمنة. 
Moreover, there is a lack of studies that consider connecting the food content and the package design attractiveness. Children find junk food visually more attractive, well packaged and better promoted in comparison with healthy food [15].

As packaging can influence children's food preferences and inspire demand in the same way that advertising can, then it is logical that restrictions should be placed on the packaging of children's foods in order to take a further step towards combating childhood obesity. Therefore, [16] recommended restrictions on advertising of unhealthy foods to children have already been imposed in different countries. Accordingly, it is necessary to strictly regulate package design of products targeted at children-health/nutrition claims as indicated by the relevance of package design on children's perception of food products should be acknowledged in public policies and restrictions are necessary on the packaging of unhealthy foods.

Therefore, additional empirical evidence of the extent to which package design influences children's preferences and perception of healthfulness is needed to support the development of appropriate and effective public policies.

\section{REFERENCES}

1. Al Dhaifallah A., Mwanri L., Aljoudi A. (2015), Childhood obesity in Saudi Arabia: Opportunities and challenges, $3(1), 2-7$

2. Mehta , K. (2013) Parents' and children's perceptions of food and beverage marketing to which children are exposed, PhD Thesis, Discipline of Public Health, Flinders Prevention, Promotion and Primary Health Care, Faculty of Health Sciences, Flinders University

3. Linn, Susan \& L. Novosat, Courtney. (2008). Calories for Sale: Food Marketing to Children in the Twenty-First Century. Annals of The American Academy of Political and Social Science - ANN AMER ACAD POLIT SOC SCI. 615. 133-155. 10.1177/0002716207308487.

4. Giménez et. Al., (2017) Package design and nutritional profile of foods targeted at children in supermarkets in Montevideo, Uruguay, Cad. Saúde Pública 2017; 33(5):e00032116

5. Hawkes, C. (2010). Food packaging: the medium is the message. Public Health Nutrition, 13(2), 297.

6. Ghoshal T, Boatwright P, Cagan J. 2009. Unwrapping the good news: packaging pays, and "how"! The role of packaging in influencing product valuation. Advances in Consumer Research 8: 254-256.

7. Fitzhugh, K. and Lobstein, T. (2000), Children's Food Examined: An Analysis of 358 Products Targeted at Children, The Food Commission, London.

8. Owen, N. (2004), "Cool for kids but hot on health", Young Consumers: Insight and Ideas for Responsible Marketers, Vol. 5 No. 2, pp. 61-4.

9. Pires , C. and Agante, L. (2011)Encouraging children to eat more healthily: The influence of packaging 10 (3), 161-168

10. Young S. 2004. Winning at retail: research insights to improve the packaging of children's products. Young Consumers: Insight and Ideas for Responsible Marketers 5(1): 17-22.

11. Underwood RL, Klein NM. 2002. Packaging as brand communication: effects of product pictures on consumer responses to the package and brand. Journal of Marketing Theory \& Practice 10(4): 58-69.

12. Ogba,I. Johnson,R. (2010) "How packaging affects the product preferences of children and the buyer behaviour of their parents in the food industry", Young Consumers, Vol. 11 Issue: 1, pp.77-89, https://doi.org/10.1108/17473611011026037

13. Valajoozi,R. , Zangi, N. (2013). A review on visual and Functional criteria of pure milk for parents and their children (case study: Tehran, Iran). International Dairy Journal. 10.1108/BFJ-12-2014-0425.

14. Opara, U., Mditshwa, A. (2013) A review on the role of packaging in securing food system: Adding value to 15. food products and reducing losses and waste, African Journal of Agricultural Research , 8(22), 2621-2630

16. McKinley MC, Lowis C, Robson PJ, Wallace JMW, Morrissey M, Moran A, Livingstone MBE. 2005. It's good to talk: children's views on food and nutrition. European Journal of Clinical Nutrition 59: 542-551.

17. Hawkes C, Smith TG, Jewell J, Wardle J, Hammond RA, Friel S, et al. (2015) Smart policies for obesity prevention. Lancet; 385:2410-21.

18. World Health Organization. Population-based approaches to childhood obesity prevention. (2012) Geneva: 


\section{SJFA}

\subsection{Font types}

Though the children cannot read yet at this age, majority of the mothers indicated that the font style will not affect the children selection as they are young and cannot read yet. Also they believed the opposition of the children preferences in the font type.

\subsection{Use of Cartoony Characters}

A systematic review of character marketing's effects on children's cognitive, behavioral, and health outcomes concluded that 3- to 6-year-old children preferred products with (vs without) characters. [12] Showed that 50\% of the mothers pointed that their children influenced by product specific characters on packaging. The rationale from socio-cognitive theories and a parasocial interactions model is that positive associations children have with their familiar and likable characters will transfer to the brand or product, producing increased trust, loyalty, recognition, and preference.

The results of the present study indicated that the majority of the children (84\%) selected packages with characters and $83 \%$ of the mothers agreed on that. $74 \%$ selected cartoony characters that they are already familiar with such as Disney characters more than animals or other unknown character to them and the majority of the mothers agreed on that as well.

\subsection{Use of images}

$91 \%$ of the children and the same percentage of the mothers both confirmed that importance of images on the packaging design for children.

\subsection{Branding}

Literature indicated that the brand is one of the important marketing factors to the children aged 34 years old. The branded food with attracting packaging and advertisement always attract the children. This demonstrates that brand identity can influence young children's taste perceptions as supported by the experimentation of [14]. However, $73 \%$ of the mothers believed that their children will not notice the brand and this criterion is of less importance among children's group in comparison to the parents' group.

While the findings of the present results are consistent with literature to regulate marketing to young children and showed that children are affected by a brand name and non-physical characteristics of a given product despite of their age and limited knowledge of reading.

\section{CONCLUSIONS}

Packaging has both a logistical and a marketing function by being a medium for conveying attractive messages or images to draw consumers 'attention and protecting the product throughout the distribution channel. The contribution of package design to the marketing of child-oriented products has been studied by several researchers. As it is important to use the children preferences by combining colors, typography, images and characters to enable children to relate to the product and feel that it is clearly communicating to them. However, there is a lack of studies that consider the involvement of the child in the design of the packaging targeted to them. This study investigated the children preferences in these visual communication aspects. The study's findings pointed the differences between the design preferences from the mothers and the child perspective. Thus, to design attractive packages for children it is highly recommended to involve children in the early stages of the design process (implement the Child centered design approach). 


\subsubsection{Use of images}

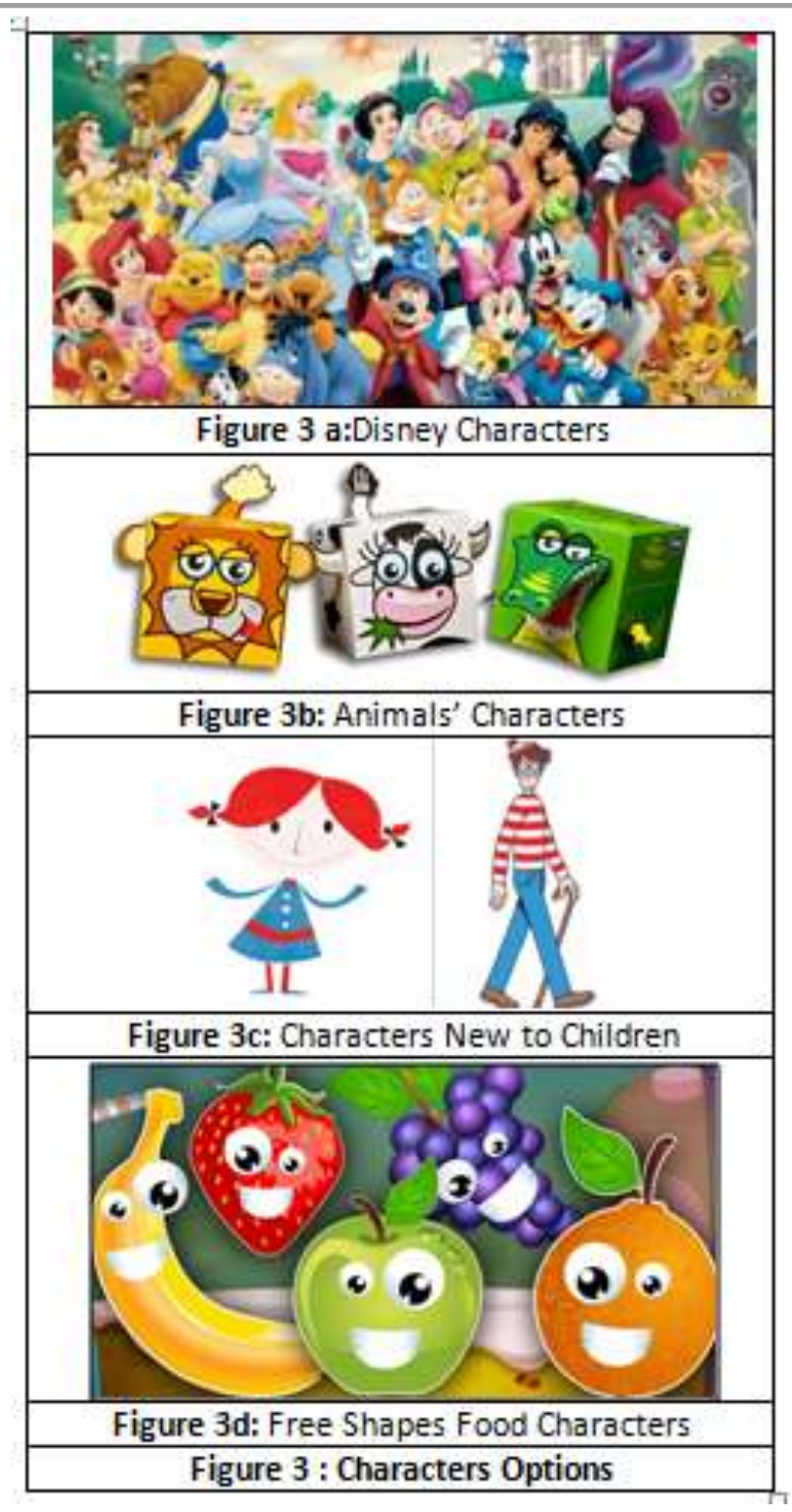

213 out of 233 children selected packages with images. While 20 selected packages with text only.

\subsubsection{Brand}

109 out of 233 children selected the packages that they are familiar with its brand.

\subsection{Package Design Visual Communication Characteristics From The Mother's Perspective}

\subsubsection{Color}

76 out of 134 mothers indicated that the color of the package is an important factor considered when selecting between the packages. 85 out of 134 mothers believed that their children preferred pastel colors, while 49 out of 134 mothers believed that their children preferred basic colors.

\subsubsection{Font type}


96 out of 134 mothers indicated that the font style will not affect the children selection as they are young and cannot read yet. However, 112 out of 134 mothers believed that if the children will select they prefer Serif font types, while 22 out of 134 mothers believed that their children preferred SansSerif font types.

\subsubsection{Use of cartoon characters}

112 out of 134 mothers' indicated that their children preferred packaging with characters. 104 out of 134 mothers believed that their children preferred Disney characters. While 18 out of 134 mothers believed that their children prefer animals characters and only 12 mothers believed that their children preferred free shapes food characters.

\subsubsection{Use of images}

122 out of 134 mothers' indicated that their children preferred packaging with images.

\subsubsection{Brand}

98 out of 134 mothers believed that their purchase decision as mothers will be affected by the brand but this factor will not be noticed by the children as they assumed that this criterion is of less importance among children's group in comparison to the parents' group.

\section{DISCUSSION}

Packaging has a great potential in influencing consumers. As indicated by [11] it is an undervalued marketing tool able to communicate product benefits, change consumer beliefs and encourage the purchase as it serves no longer as a mere protection and preservation. The packaging is the first characteristic of the food the children sees in the store, and mostly had a major link to advertising which is aimed at getting the children to pick a specific variety. Children influenced by packaging designs as pointed by [12]. Packaging design consisted of visual and functional factors. [13] indicated that visual factors mostly refer to color, information presented on the packaging, the font style and letter writing. Marketers therefore constantly use attractive visual imagery, recognizable characters, color and design to ensure their product stands out to children. Thus, these visual factors were studied and their importance was prioritized between children and mothers. It was concluded that in order for an item of food to be purchased by the mother, it must look appealing to the child so that the mother can be assured that the child will eat it and unnecessary waste be avoided. This study considers the children requirements in the package design comparing to mothers believe as follows:

\subsection{Colors}

The use of colors is one of the most advantageous factors to consider in the packaging design for children. [12] Pointed that color has a high impact on children attraction toward packaged food. The results of the study supported that the color was one of the high importance criteria for children aged 34 years old. $88.4 \%$ of the children indicated that the color affects their package selections while $57 \%$ of the mothers believed that the color is an important criterion in the children colors selection. Also $63 \%$ of the mothers pointed the importance of pastel colors while the majority of the children preferred packaging with basic colors. Thus, this criterion is more important in children's group in comparison to the parents' group and the preferences are different. This supported [13] who mentioned that the packaging color has different effects on the purchase of people with various ranges of age. 


\section{RESULTS}

Five factors of background color, font style, use of cartoon characters, use of images, and brand were selected to investigate their comparison and priority among the target groups.

\subsection{Package Design Visual Communication Characteristics From The Children's Perspective}

\subsubsection{Color}

206 out of 233 children indicated that the color of the package is an important factor considered when selecting between the packages. 198 out of 233 children preferred basic colors while 35 out of 233 children selected pastel color. Figure 1 shows the color scheme tool used to collect children preferences as it represents the basic and the pastel colors.

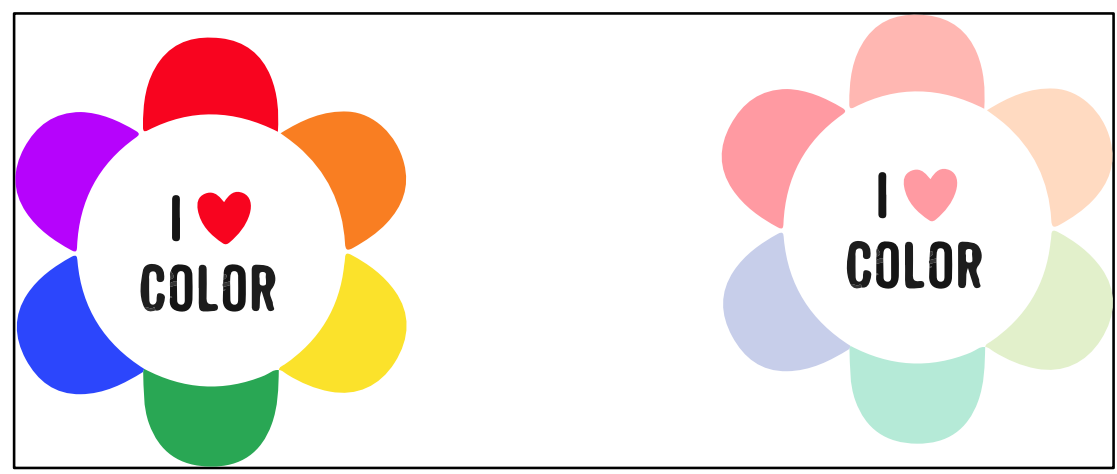

\subsubsection{Font type}

Fig 1: Color Scheme Tool Used to Collect Children Preferences

168 out of 233 children preferred the sans serif font type while 47 out of 233 children preferred serif font type. Figure 2 shows the different font type options discussed with children.

\section{Font Type \\ Font Type}

Fig 2: Font Type: Serif vs. Sans Serif

\subsubsection{Use of cartoon characters}

197 out of 233 children selected packages with characters. 174 out of 233 children selected cartoony characters that they are already familiar with such as Disney characters. While 59 out of 233 children selected children characters new to them of which 39 selected free shapes food characters and 20 selected animals' characters. Figure 3 shows the different characters options provided to the children. 


\section{SJFA}

marketing communications campaign. In fact, emotions evoked by an appealing packaging are stronger and more positive than those evoked by ordinary packaging [6].

[7], [8] confirmed that packaging affects children's food preferences. Also [5] pointed some of the packaging elements that used in design to attract children to food, such as animated characters and toys from television, movies they like, also their favorite sports teams and special events. These marketing strategies have been reported to encourage children to think that products are tastier, healthier, funnier, and more appropriate for them, increasing their liking and willingness to consume.

At the age of 3-4 years, children seem to have a very low desire to eat anything and most healthy food packaging tends to communicate only to adults, whereas unhealthy food is being increasingly marketed toward children by using appealing colors, words and symbols [9].

Researchers have demonstrated the importance of packaging in influencing purchase decisions, especially in the case of products for children [10] However, most of the existing literature addressed the design of children food packaging from the parents perspective, while there is a significant difference between the visual standards of packaging design among the groups of parents and children which could play an important role in designers' and marketers' decision makings on their design and marketing strategies, respectively. Thus, investigating the design features of the packaging of children's targeted food products from the children perspective is still necessary to aid policy design and development.

\section{AIMS AND OBJECTIVES}

The present study aims to investigate the packaging design features of the children's food from the perspective of children aged 3-4 years old in Saudi Arabia.

\section{Objectives:}

1. To investigate the children package design requirements in the five aspects: color, font style, use of cartoon characters , use of images, and brand;

2. To investigate the parents package design requirements in the five aspects: color, font style, use of cartoon characters, use of images, and brand;

3. To compare the parents and the children design requirements of food packaging targeted to children aged 3 to 4 years old in Saudi Arabia;

\section{METHEODLOGY}

Most of the exiting studies associated with children food packaging emanate data from parents rather than their children. However, this study collected the data from the children as the main end user. 233 preschool children aged 3 to 4 years in Jeddah, Saudi Arabia participated in the study. The students meeting and data collection were undertaken in 7 Kindergarten pre-schools in the city of JeddahEastern region of Saudi Arabia. In conducting this study, focus group were administered for data collection. The suitability of this approach is based on methods and approaches employed in similar studies. Moreover, 134 mothers who has children in the age of 3-4 participated in the study. They were interviewed to discuss the packaging design visual characteristics and prioritize the five aspects according to their belief in their child preferences. 


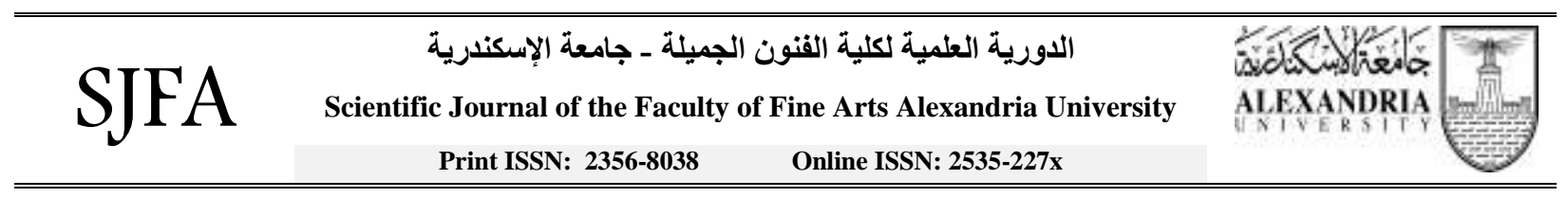

\title{
FOOD PACKGING DESIGN FOR CHILDREN AGED 3-4 YEARS IN SAUDI ARABIA
}

\author{
Ruba. H. Abu Hasna ${ }^{1}$
}

\begin{abstract}
This study investigates the design features of food packaging targeted to children from the perspective of the children and the mothers. The majority of the exiting studies related to children food packaging emanate data from parents rather than their children. However, this study collected the data from 233 preschool children aged 3-4 years using focus group in their kindergarten school in the city of Jeddah in Saudi Arabia. Moreover, 134 mothers who have children in the age of 3-4 were interviewed to discuss the packaging design visual characteristics and prioritize the five aspects: 1) background color 2) font style 3) use of cartoon characters, 4) use of images, and 5) brand according to their belief in their child preferences. The findings pointed the differences between the design preferences from the mothers and the child perspective. Hence, to design attractive packages for children it is highly recommended to implement the child centered design approach.
\end{abstract}

KEYWORDS: Children centered design, Packaging Design, food packaging, children food, children obesity.

\section{INTRODUCTION}

There is a considerable increase in children level of obesity in Saudi Arabia. This supports the international trend of worrying childhood obesity [1].

Children are an integral part of consumption culture; they are intensely involved in family purchase routines and decisions [2]. Children are extensively marketed to by food manufacturers [3]. According to reports of [4] a considerable share of food companies' advertising budget is spent on advertisements targeted at children through TV, radio, the internet, and magazines. However, marketing strategies are not limited to broadcast and digital advertising, but also include packaging, sponsorship, and merchandising. Thus, there is a significant implication for children food marketing practices in Saudi Arabia.

Packaging is a marketing vehicle [5] and no longer simply serves a functional purpose. It becomes an important aspect of branding positioning and related communication as part of an integrated

1 Jeddah International College, Design Department, Associate Professor rhabuhasna@gmail.com 